\title{
Psychiatric and Psychosocial Outcome of Orthotopic Liver Transplantation
}

\author{
Hans-Bernd Rothenhäuslera Sigrid Ehrentrauta Hans-Peter Kapfhammera \\ Christina Lang a Reinhart Zachoval ${ }^{b}$ Manfred Bilzer ${ }^{b}$ Gustav Schelling ${ }^{c}$ \\ Alexander L. Gerbes ${ }^{b}$ \\ Departments of aPsychiatry, b Medicine II, cAnesthesiology, Ludwig-Maximilians University of Munich, \\ Munich, Germany
}

\section{Key Words}

Liver transplantation . Psychiatric morbidity .

Posttraumatic stress disorder . Health-related quality of life - Cognitive performance . Consultation-liaison psychiatry

\begin{abstract}
Background: The study aimed to explore the prevalence of psychiatric disorders among orthotopic liver transplantation (OLT) recipients, and to investigate how psychiatric morbidity was linked to health-related quality of life (HRQOL). Methods: We recruited 75 patients who had undergone OLT a median of 3.8 years previously (range $=5-129$ months). Psychiatric morbidity was assessed using the Structural Clinical Interview for the DSM-III-R. Psychometric observer-rating and self-rating scales were administered to evaluate cognitive functioning (SKT), depressive symptomatology $\left(\mathrm{HAMD}_{17}\right)$, posttraumatic stress symptoms (PTSS-10), social support (SSS), and HRQOL (SF-36 Health Status Questionnaire). Treatment characteristics were obtained from medical records. Results: $22.7 \%$ ( $n=17$ ) of our sample had a current or probable psychiatric diagnosis according to DSMIII-R: $2.7 \%$ full posttraumatic stress disorder (PTSD) ( $\mathrm{n}=$ 2), $2.7 \%$ major depressive disorder (MDD) comorbid to
\end{abstract}

\section{KARGER}

Fax +41613061234

E-Mail karger@karger.ch

www. karger.com
(C) 2002 S. Karger AG, Basel

0033-3190/02/0715-0285\$18.50/0

Accessible online at:

www. karger.com/journals/pps full PTSD ( $\mathrm{n}=2), 1.3 \%$ MDD comorbid to partial PTSD $(n=1)$, and $16 \%$ partial PTSD $(n=12)$. Patients with PTSD symptoms demonstrated lower cognitive performance, higher severity of depressive symptoms and more unfavorable perception of social support. OLT-related PTSD symptomatology was associated with maximal decrements in HRQOL. The duration of intensive care treatment, the number of medical complications, and the occurrence of acute rejection were positively correlated with the risk of PTSD symptoms subsequent to OLT. Conclusion: OLT-related PTSD symptomatology impairing HRQOL is a complication for a subgroup of OLT recipients. Health-care providers should be aware of the possible presence of PTSD in OLT survivors.

Copyright $\odot 2002$ S. Karger AG, Basel

\section{Introduction}

Owing to the introduction of more effective immunosuppressive agents such as cyclosporine (CsA) in 1980 and tacrolimus (FK 506) in 1989, the standardization of the surgical procedure, and the significant advances in intensive care treatment, patient selection, tissue matching and organ preservation, the clinical outcome of liver transplant recipients has tremendously improved over the past
Dr. Hans-Bernd Rothenhäusler

Psychiatrische Klinik und Poliklinik der LMU München

Nussbaumstrasse 7, D-80336 Munich (Germany)

Tel. +49897095 2718, Fax +498970952715

E-Mail rothenh@kons.med.uni-muenchen.de 
15 years [1]. Orthotopic liver transplantation (OLT) is now the treatment of choice for end-stage liver disease, with 1-year survival rates in adult transplant recipients of about $85 \%$ and 9 -year survival rates of $55 \%$ in most of the 200 international centers including our Munich Liver Transplantation Group with approximately 40 transplants per annum $[2,3]$.

As transplantation surgery has dramatically advanced, the success of OLT is no longer judged solely by its effects on morbidity and mortality but by its influence on transplant recipients' psychosocial well-being [4]. In recent years, a number of outcome studies have focused on health-related quality of life (HRQOL) after liver transplantation among adults, showing that OLT is associated with improvement in HRQOL relative to the pretransplant period, but without restoring the health status levels described in the general population [5-7]. This finding has raised concern about full psychosocial rehabilitation in OLT. However, factors responsible for the persistent difference remain poorly defined. Several studies emphasized the impact of recurrence of hepatitis $\mathrm{C}$ virus $(\mathrm{HCV})$ infection [8-11], CsA neurotoxicity [12-14], and mood symptoms during corticosteroid therapy [15].

From a psychiatric point of view, clinical observations point to psychiatric problems after OLT that may impair HRQOL in liver transplant recipients [16, 17]. One study has examined psychiatric complications of the postoperative period of OLT in 63 adult liver transplant recipients. The investigators found that psychiatric morbidity was $29 \%$. Organic mental disorders were the most prevalent, especially delirium (13\%), followed by adjustment disorders $(8 \%)$, major depression (5\%) and organic anxiety disorders (3\%) [18]. Surman et al. [19] reported that $20 \%$ of 40 adult liver transplant recipients were referred for treatment of depressive disorder typically associated with deterioration of hepatic status, infectious complication or recurrence of cancer. To date, only two studies have focused specifically on psychiatric morbidity and HRQOL in adult intermediate-term survivors of OLT $[20,21]$. Commander et al. [20] found that psychiatric morbidity in the 32 liver transplant recipients was associated with significant impairment in some areas of social functioning. The prevalence rate of psychiatric morbidity was $18.8 \%$ according to Research Diagnostic Criteria [22], and major depressive disorder (MDD) accounted for two thirds of all psychiatric diagnoses. Investigating 30 liver transplant recipients, Collis et al. [21] also demonstrated that there was a significant association between psychiatric morbidity and impaired HRQOL. They recorded a prevalence figure of $26.7 \%$, using the Clinical
Interview Schedule [23]. Mild mixed anxiety and depressive disorders accounted for $50 \%$, severe depressive disorder for $12.5 \%$ of all psychiatric diagnoses.

The overall aim of the present outcome study was to examine concurrently psychiatric morbidity including cognitive deficits and psychopathologically relevant dimensions, and quality of life in intermediate-term survivors of OLT, and to investigate how psychiatric morbidity is related to HRQOL. As previous research has documented that anxiety and depressive symptomatology are most commonly present in a substantial portion of liver transplant recipients, we were specifically interested in the prevalence rate of posttraumatic stress disorder (PTSD) in our patient population. In our view, it is conceivable that OLT representing a 'high-tech' medical procedure associated with the risk of a variety of medical complications (e.g. acute rejection, bleeding, infections) during the intensive care unit (ICU) stay might be a traumatic stressor that is capable of producing posttraumatic stress symptoms. We therefore examined variables such as the extent of medical complications during the ICU course subsequent to OLT, length of ICU stay, duration of waiting period for OLT, type of liver failure, history of retransplantation and of recurrence of $\mathrm{HBV} / \mathrm{HCV}$, and preexisting trauma that may contribute in some way to the development of posttraumatic stress symptoms in OLT recipients. To our knowledge, this is the first study that has addressed posttraumatic stress responses after OLT in adult liver transplant recipients, and only one previous study has examined this issue in older children [24] to date.

\section{Subjects and Methods}

\section{Subjects and Procedure}

Between March 1996 and October 1997, the outpatient clinic of the Department of Medicine II at the Klinikum Grosshadern, the tertiary care center of the Ludwig-Maximilians University, Munich, Germany, treated 81 adult liver transplant recipients (age 16 or older) who survived more than 5 months after undergoing OLT at our transplantation center, who had CsA or tacrolimus (FK 506) concentrations in blood within therapeutic range, and who did not receive steroid therapy. These 81 patients were approached by their physicians from our outpatient clinic to participate. The refusal rate for the present sample was $7.4 \%(n=6)$. Respondents were indistinguishable from the few nonrespondents on transplant-related and sociodemographic characteristics. Those agreeing were then contacted by the research assistants, the study was explained, and informed consent was obtained. Consenting patients were interviewed by experienced consultation-liaison psychiatrists (H.-B.R., H.-P.K.), and completed the research battery at the time of a regularly scheduled medical follow-up examination at the Klinikum Gross- 
hadern. The battery included a brief author-compiled questionnaire, a structured clinical interview, self-report questionnaires, and psychometric observer-rating scales. The study was approved by the Institutional Review Board of our institution. Data protection met the standard set by German law.

\section{Sociodemographic and Clinical Characteristics}

Information about patient and treatment characteristics were obtained from a brief author-compiled questionnaire and from the medical record. Demographic variables included age, gender, race, marital status, and employment status at the time of the psychiatric assessment. Marital status was categorized as married or living with a spouse, single, divorced, or widowed. The patient's employment status was rated with respect to the following criteria: (a) full-time/parttime employment, (b) unemployment, (c) retirement, (d) homemakers in lieu of paid employment, and (e) disabled from work because of health problems. According to WHO [25], disability is the consequence of impairment, in terms of functional performance and activity by the afflicted person. Hence, we classified the OLT recipients as disabled if they met criterion (e). Clinical characteristics included the primary liver disease that led to end-stage liver disease and necessitated OLT, as determined by the results of serologic, biochemical, and histopathologic evaluations prior to the transplant surgery. History of medical complications during ICU treatment following OLT was obtained from the medical record. They comprised acute rejection, gastrointestinal bleeding, acute renal failure, acute respiratory distress syndrome, acute cardiovascular disturbances, delirium, viral, mycotic and/or bacterial infections. Further, the waiting period for OLT, duration of ICU treatment following OLT, history of retransplantation, history of recurrence of $\mathrm{HBV}$ or HCV positivity after OLT, and the type of liver failure (acute vs. chronic) were recorded. All medical information regarding treatment characteristics and history of medical complications following OLT was collected by experienced physicians from the outpatient clinic of the Department of Medicine II (R.Z., M.B.).

\section{Psychiatric Diagnosis}

Two experienced psychiatrists from the consultation-liaison service (H.-B.R., H.-P.K.) conducted the Structural Clinical Interview for the DSM-III-R (SCID) [26, 27] to assess current and past psychiatric diagnoses according to DSM-III-R criteria [28]. A sample of 15 randomly selected cases assessed by both raters [ 1 conducting the interview (H.-B.R.) and 1 observing (H.-P.K.)] was used to assess interrater reliability. The kappa for these 15 patients was 0.84 , and was considered to be adequate.

While psychiatric disorders other than PTSD were only assigned to the OLT recipients when DSM-III-R criteria were completely met, in the case of PTSD, we differentiated between a full PTSD and a subthreshold or partial PTSD. According to our concept, OLT recipients received a subthreshold disorder of partial PTSD if they failed to meet all the diagnostic criteria B (reexperiencing phenomena), C (symptoms of avoidance and emotional numbing), D (symptoms of increased arousal), but fulfilled two of these three key responses to trauma and, additionally, the criteria A (trauma criterion), E (duration of the disturbance is more than 1 month), and $\mathrm{F}$ (the disturbance causes clinically significant distress or psychosocial impairment). The trauma criterion $A$ was homogeneously defined as $O L T$. In order to validly assess any pre-OLT relevant trauma or any post-OLT exposure to traditional traumatic experiences other than our defined criterion A stressor event for PTSD itself, we used the PTSD supple- ment as included in the SCID. Since PTSD symptoms were rearranged, but not changed, between DSM-III-R and DSM-IV [29], we were able to generate DSM-IV diagnoses for PTSD.

\section{Psychometric Tests}

After completion of the SCID, pertinent psychometric observerrating and self-rating scales were administered to assess cognitive functioning, depressive symptomatology, posttraumatic stress symptoms, social support, and HRQOL.

The neuropsychological evaluation was based on the SKT, a short cognitive performance test including 9 subtests for assessing deficits of memory and attention $[30,31]$. Norm values range from 0 to 27 , and differentiate between profound (24-27), severe (19-23), moderate (14-18), mild (9-13), questionable (5-8) cognitive impairments, and no cognitive deficits (0-4). Published reliability data varied between 0.86 and 0.88 [32]. The German version of the 17 -item Hamilton rating scale for depression $\left(\mathrm{HAMD}_{17}\right)$ was used to measure the severity of depressive symptomatology [33, 34]. According to Paykel [35], a score of 18 points or more typically equals major depression, and the range of 13-17 points is generally used to indicate probable major depression. The Posttraumatic Stress Syndrome 10-Questions Inventory (PTSS-10) is a self-rating 10-item scale based on the DSM-III [36] that measures the presence and intensity of posttraumatic stress symptoms [37]. The German version of the PTSS-10 (range: 10-70 points) has been successfully validated in patients with PTSD after prolonged ICU treatment, and has proved to be a reliable scale (Crohnbach's alpha $=0.93$ ). An optimal cut-off score of 35 points of the questionnaire for diagnosis of PTSD has been noted [38]. To evaluate the patients' perception of a range of socially supportive experiences, the Social Support Scale (SSS) [39] was used. The German version of the SSS [40] is a self-report scale with 19 items on a scale from 0 (never) to 4 (always), and a sum score range from 0 to 76 points. Higher scores reflect a more favorable perception of social support. To assess HRQOL after OLT in adult liver transplant recipients, we applied the psychometrically validated German translation of the Medical Outcome Study Short Form (SF36) $[41,42]$. The SF-36 is a 36 -item, self-rating questionnaire that covers 8 health-related domains. Each domain yields a score ranging from 0 to 100 (best). Published internal consistency data of the SF-36 exceeded 0.8 in the vast majority of the studies $[43,44]$.

\section{Control Group for HRQOL Measurement}

Control subjects were randomly selected from a large epidemiological database $(n=3,000)$ used to provide standard values for the SF-36 in a German population. Our HRQOL control group $(n=75)$ represented age and gender-identical healthy subjects whose sociodemographic characteristics did not differ from the study sample.

\section{Statistical Analyses}

This outcome study examines the intermediate-term status in a selected cohort of OLT recipients. The OLT recipients $(n=75)$ were divided into three subcategories of patients based on whether the criteria for PTSD according to DSM-III-R and DSM-IV were completely met, partially met, or not met at a median time of 3.8 years after OLT. SF-36 data were compared with data from an age and gendermatched control group of 75 healthy subjects. All statistical analyses were performed using SPSS 10.0 for Windows (SPSS Inc., Chicago, Ill., USA). Descriptive statistics were carried out on demographic, treatment-related, and psychometric data (SF-36, PTSS-10, SKT, HAMD $_{17}$, SSS scores), and are presented as median \pm SD or mean 
Table 1. Sociodemographic characteristics of adult OLT recipients according to the diagnostic status of PTSD at the time of psychiatric assessment

\begin{tabular}{|c|c|c|c|c|c|}
\hline Category & $\begin{array}{l}\text { Total sample } \\
(\mathrm{n}=75)\end{array}$ & $\begin{array}{l}\text { No PTSD } \\
(\mathrm{n}=58)\end{array}$ & $\begin{array}{l}\text { Partial PTSD } \\
(\mathrm{n}=13)\end{array}$ & $\begin{array}{l}\text { Full PTSD } \\
(n=4)\end{array}$ & $\mathrm{p}$ \\
\hline \multicolumn{6}{|l|}{ Gender } \\
\hline Male/female & $43 / 32$ & $33 / 25$ & $6 / 7$ & $4 / 0$ & $0.162^{1}$ \\
\hline \multicolumn{6}{|l|}{ Age } \\
\hline Median, years & 54 & 55 & 51 & 44.5 & \multirow{3}{*}{$0.198^{2}$} \\
\hline SD & 10.9 & 11.1 & 9.3 & 9.9 & \\
\hline Range, years & $16-71$ & $16-71$ & $35-70$ & $31-54$ & \\
\hline \multicolumn{6}{|c|}{ Employment status } \\
\hline Disabled & 27 & 19 & 6 & 2 & \multirow[b]{2}{*}{$0.553^{1}$} \\
\hline Not disabled & 48 & 39 & 7 & 2 & \\
\hline \multicolumn{6}{|l|}{ Marital status } \\
\hline Single & 11 & 8 & 2 & 1 & \multirow{4}{*}{$0.294^{1}$} \\
\hline Married & 59 & 47 & 10 & 2 & \\
\hline Widowed & 2 & 1 & 1 & - & \\
\hline Divorced & 3 & 2 & - & 1 & \\
\hline \multirow{2}{*}{\multicolumn{6}{|c|}{$1 \quad \chi^{2}$ tests. }} \\
\hline 2 Kruskal-Wall & & & & & \\
\hline
\end{tabular}

$\pm \mathrm{SD}$, and ranges (minimum and maximum values, or 25 th and 75 th percentiles) when appropriate. Kruskal-Wallis one-way analysis was applied between the three subgroups of OLT recipients with full, partial and no PTSD, and SKT, HAMD, PTSS-10, SF-36 scores, age, time interval between OLT and psychiatric evaluation, ICU days, waiting period for OLT, and number of medical complications during ICU treatment. In this context, pairwise multiple comparison procedures (Bonferroni) were used in order to determine which subgroups were significantly different. In the analysis of significant distribution differences for categorical variables between the three subgroups, we applied $\chi^{2}$ tests. The nonparametric Wilcoxon signed rank test was used for comparison of SF-36 data between the entire sample of 75 OLT recipients and the age and gender-matched control group of 75 healthy subjects. All tests were two-tailed. Significance was set at $p=0.05$ for all analyses.

\section{Results}

\section{Clinical Status}

A total of $44 \%(n=33)$ of our entire sample $(n=75)$ met the criteria for any lifetime diagnosis on the SCID: alcohol abuse/dependence ( $\mathrm{n}=24 ; 32 \%$ of the sample), other drug abuse/dependence ( $\mathrm{n}=3 ; 4 \%$ of the sample), depressive disorders NOS ( $\mathrm{n}=3 ; 4 \%$ of the sample), $\operatorname{MDD}(\mathrm{n}=2 ; 2.7 \%$ of the sample), and bipolar affective disorder ( $\mathrm{n}=1 ; 1.3 \%$ of the sample). Prior psychiatric history did not reveal any lifetime diagnosis of PTSD in our sample. $2.7 \%(\mathrm{n}=2)$ of our sample reported any lifetime exposure to traditional stressors in terms of physical attack.

$22.7 \%(n=17)$ of our entire sample $(n=75)$ had a current or probable psychiatric diagnosis on the SCID: full PTSD ( $n=2 ; 2.7 \%$ of the sample), MDD comorbid to partial PTSD ( $n=1 ; 1.3 \%$ of the sample), and partial PTSD ( $n=12 ; 16.0 \%$ of the sample). Those participants with lifetime histories of alcohol abuse/dependence or other drug abuse/dependence were fully remitted at the time of psychiatric assessment. Of the 13 current cases of partial PTSD, 5 had histories of alcohol abuse/dependence and 3 had histories of depressive disorders NOS. Of the 4 current cases of full PTSD, 2 had histories of MDD. None of the 2 patients reporting lifetime exposure to traditional stressors met the criteria for full or partial PTSD.

\section{Sociodemographic and Treatment Characteristics}

Seventy-five out of 81 eligible OLT recipients were enrolled in this psychiatric outcome study. All participants ( 32 females and 43 males) were Caucasian, and the mean age was 52.2 years $(\mathrm{SD}=10.9)$. The median time interval between OLT and psychiatric assessment was 46 months ( $\mathrm{SD}=27.9$; range 5-129 months). Table 1 summarizes the sociodemographic characteristics, and table 2 
Table 2. Treatment characteristics of adult OLT recipients according to the diagnostic status of PTSD at the time of psychiatric assessment

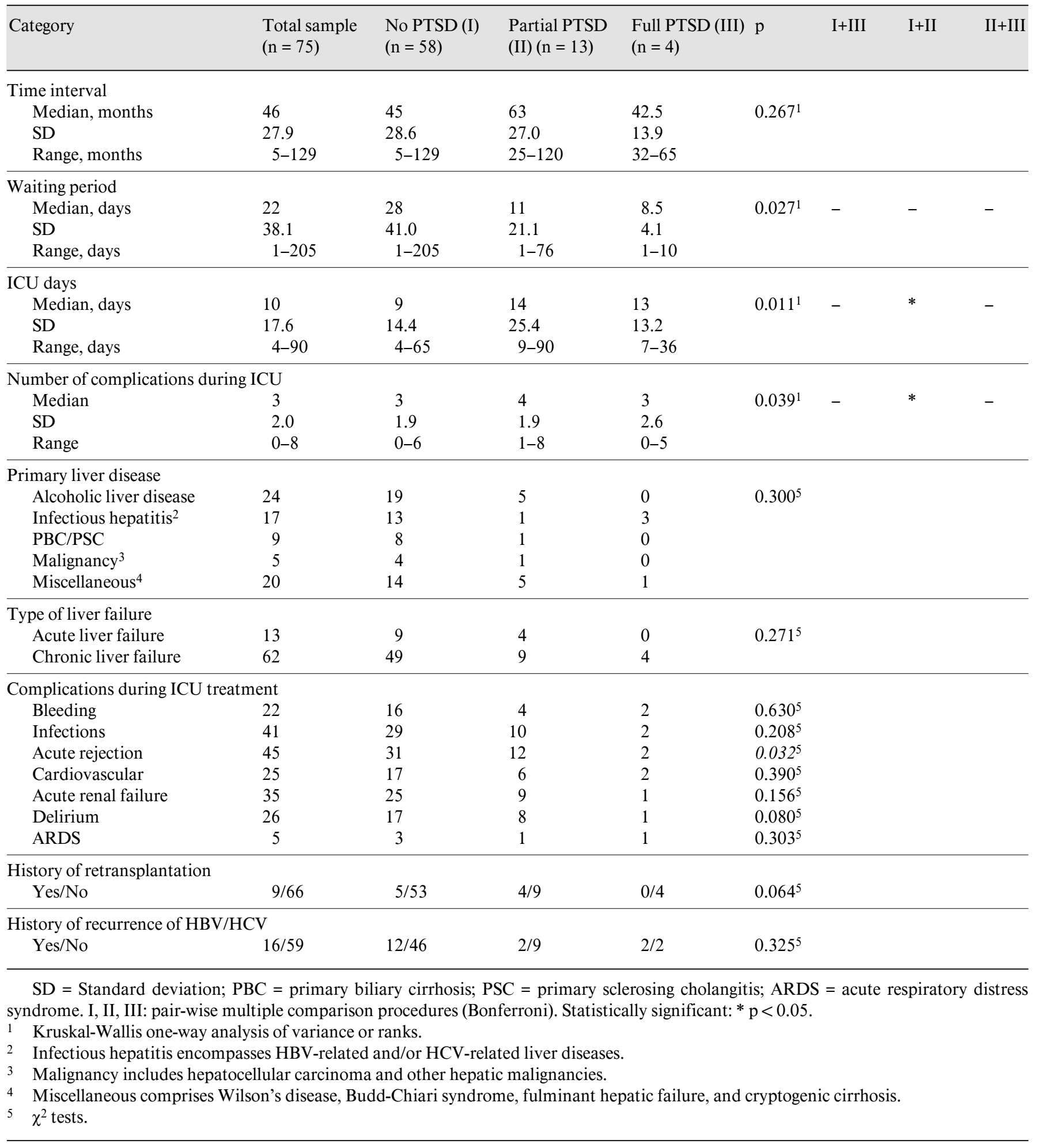


Table 3. Test-psychological correlates of adult OLT recipients according to the diagnostic status of PTSD at the time of psychiatric assessment

\begin{tabular}{|c|c|c|c|c|c|c|c|c|}
\hline Category & $\begin{array}{l}\text { Total sample } \\
(\mathrm{n}=75)\end{array}$ & $\begin{array}{l}\text { No PTSD (I) } \\
(\mathrm{n}=58)\end{array}$ & $\begin{array}{l}\text { Partial PTSD (II) } \\
(\mathrm{n}=13)\end{array}$ & $\begin{array}{l}\text { Full PTSD (III) } \\
(\mathrm{n}=4)\end{array}$ & $\mathrm{p}$ & I+III & $\mathrm{I}+\mathrm{II}$ & II+III \\
\hline SKT & $\begin{array}{l}2.0 \\
(0.0-14.0)\end{array}$ & $\begin{array}{l}1.0 \\
(0.0-8.0)\end{array}$ & $\begin{array}{l}3.0 \\
(1.0-14.0)\end{array}$ & $\begin{array}{l}5.5 \\
(4.0-8.0)\end{array}$ & ++ & $*$ & $*$ & - \\
\hline HAM-D 17 & $\begin{array}{l}4.0 \\
(0.0-31.0)\end{array}$ & $\begin{array}{l}2.0 \\
(0.0-9.0)\end{array}$ & $\begin{array}{l}7.0 \\
(3.0-30.0)\end{array}$ & $\begin{array}{l}22.0 \\
(11.0-31.0)\end{array}$ & +++ & $*$ & $*$ & $*$ \\
\hline PTSS-10 & $\begin{array}{l}18.0 \\
(10.0-52.0)\end{array}$ & $\begin{array}{l}16.0 \\
(10.0-24.0)\end{array}$ & $\begin{array}{l}29.0 \\
(25.0-33.0)\end{array}$ & $\begin{array}{l}47.0 \\
(36.0-52.0)\end{array}$ & +++ & $*$ & $*$ & $*$ \\
\hline SSS & $\begin{array}{l}69.0 \\
(14.0-76.0)\end{array}$ & $\begin{array}{l}71.0 \\
(14.0-76.0)\end{array}$ & $\begin{array}{l}63.0 \\
(28.0-76.0)\end{array}$ & $\begin{array}{l}33.5 \\
(14.0-62.0)\end{array}$ & ++ & $*$ & - & $*$ \\
\hline
\end{tabular}

Values are median; scores in parentheses indicate minimum and maximum. $+++\mathrm{p}<0.001 ;++\mathrm{p}<0.01 ;+\mathrm{p}<0.05$ according to KruskalWallis one-way analysis of variance or ranks. I, II, III: pair-wise multiple comparison procedures (Bonferroni). Statistically significant: $* \mathrm{p}<0.05$.

presents information on the treatment characteristics of the whole study sample and according to the diagnostic status of PTSD at the time of psychiatric assessment (see clinical status). The analysis of the employment status of the entire sample showed that 21 of 75 OLT recipients (28\%) were full-time or part-time employed, $16(21.3 \%)$ were retired due to age-related reasons, $9(12 \%)$ were homemakers in lieu of paid employment, $2(2.7 \%)$ were unemployed, and 27 (36\%) were disabled from work because of health.

\section{Results of Psychological Tests}

Test-psychological correlates of our adult OLT recipients are depicted in table 3 for the entire sample and according to the diagnostic status of PTSD at the time of psychiatric assessment.

We found that the mean SKT total score (expressed as norm values) from the whole sample of adult OLT recipients was $2.75(\mathrm{SD}=2.75$; median value $=2.0$; range 0.0 14.0) at a median time of 3.8 years after OLT, and lay well under the cut-off point of 5 . However, $17.3 \%(n=13)$ of the entire sample showed cognitive impairments as measured on the SKT (mean SKT total score $=7.54, \mathrm{SD}=$ 2.88, range 5.0-14.0). No extreme and severe cognitive deficits were recorded. A significant difference in cognitive functioning between the subgroups was evident (Kruskal-Wallis, $\mathrm{H}=13.733$, $\mathrm{df}=2, \mathrm{p}<0.01$ ). Patients without PTSD had significantly lower scores than those with partial or full PTSD on the SKT. On the 17-item HAMD, the entire sample of OLT recipients showed a mean score of $5.33(\mathrm{SD}=6.47$; median value 4.0 ; range
$0.0-31.0$ ). Four patients scored $\geq 18$, and 2 patients fell within the range of 13-17 points on the HAMD ${ }_{17}$. However, only 3 out of these 6 patients fulfilled the diagnostic criteria of MDD according to SCID. As illustrated on table 3 , a significant difference in the intensity of depressive symptomatology between the three subgroups was noted (Kruskal-Wallis, $\mathrm{H}=26.938$, df $=2, \mathrm{p}<0.001$ ): patients with partial PTSD had significantly higher scores than those without PTSD, and significantly lower scores

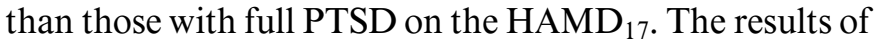
the PTSS-10 questionnaire in our sample discriminated well with respect to the diagnostic status of PTSD according to SCID (Kruskal-Wallis, $\mathrm{H}=39.504$, df $=2$, $\mathrm{p}<$ 0.001). Adult OLT recipients with full PTSD scored an average of 45.5 points $(\mathrm{SD}=6.95$; median value $=47.0$; range 36.0-52.0), and lay well above the cut-off score of 35 . As shown in table 3 , we recorded a significant difference in our subjects' perception of supportive relationships between the three subgroups (Kruskal-Wallis, $\mathrm{H}=$ $12.476, \mathrm{df}=2, \mathrm{p}<0.01$ ). Patients with full PTSD revealed a marked tendency to perceive supportive relationships less favorably than patients with partial PTSD and patients without PTSD on the SSS.

As shown in figure 1, our 75 participants performed significantly worse on all health-related domains at a median time of 3.8 years after OLT, when compared with 75 age and gender-matched healthy controls [Wilcoxon signed rank test: physical functioning $(\mathrm{PF}), \mathrm{Z}=-7.385$, $\mathrm{p}<0.001$; role-physical $(\mathrm{RP}), \mathrm{Z}=-5.420, \mathrm{p}<0.001$; bodily pain (BP), $\mathrm{Z}=-5.400, \mathrm{p}<0.001$; general health $(\mathrm{GH})$, $\mathrm{Z}=-6.160, \mathrm{p}<0.001 ;$ vitality $(\mathrm{V}), \mathrm{Z}=-5.131, \mathrm{p}<0.001$; 
Fig. 1. Mean scores \pm standard errors on the SF-36 at the time of psychiatric assessment data ( $\mathrm{n}=75$ OLT recipients) compared with 75 age- and gender-matched healthy controls. Normal score $=100 .{ }^{* * *} \mathrm{p}<0.001$ (Wilcoxon signed rank test); ** $\mathrm{p}<0.01$ (Wilcoxon signed rank test).

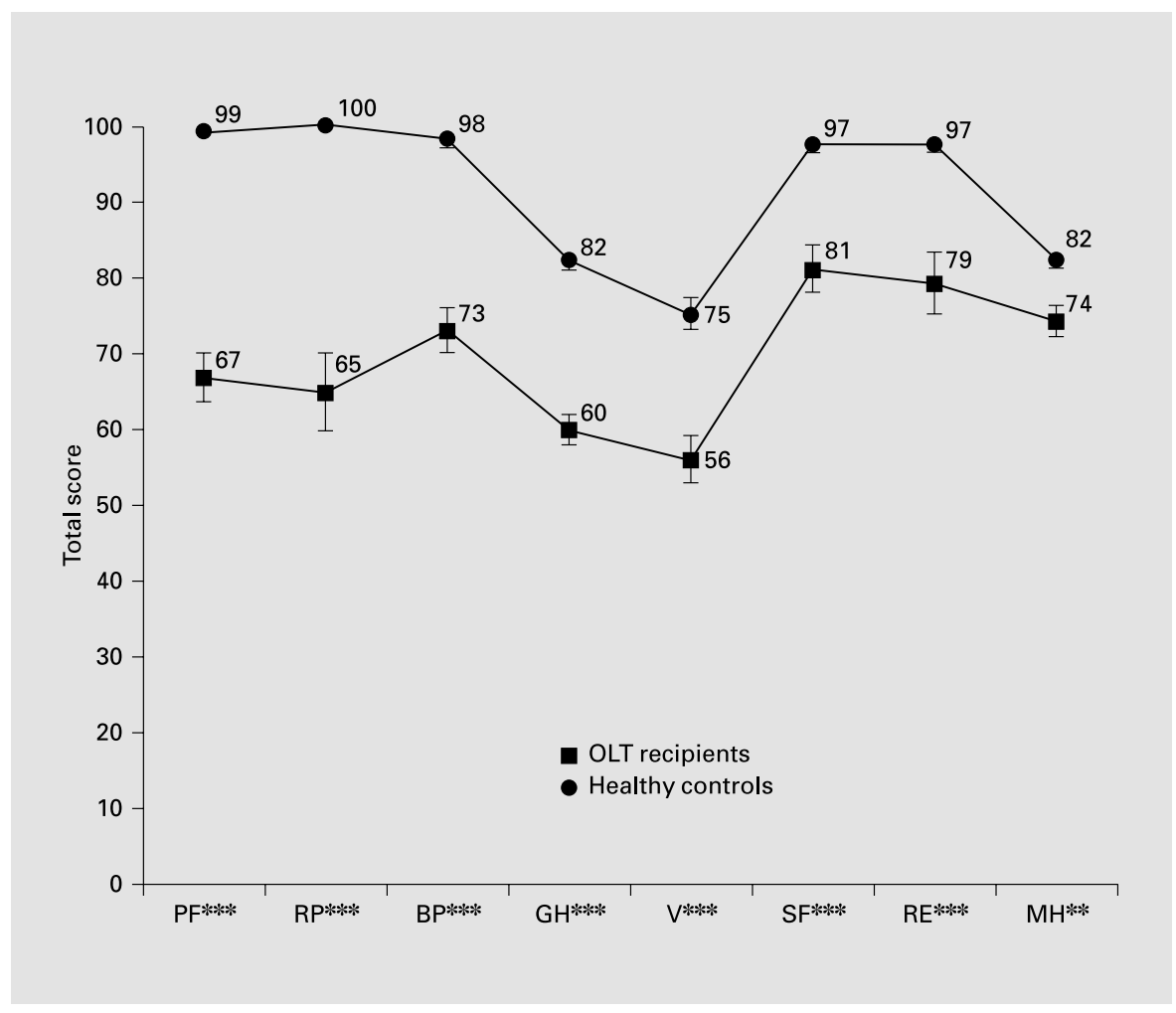

social functioning $(\mathrm{SF}), \mathrm{Z}=-4.576, \mathrm{p}<0.001$; role-emotional (RE), $\mathrm{Z}=-3.869, \mathrm{p}<0.001$; mental health $(\mathrm{MH})$, $\mathrm{Z}=-2.582, \mathrm{p}<0.01]$.

Among the studied adult OLT recipients, patients with full PTSD showed the lowest HRQOL, followed by patients with partial PTSD, and patients without PTSD (fig. 2). Significant differences in PF (Kruskal-Wallis, $\mathrm{H}=$ 8.735, df $=2, p<0.05$ ), RP (Kruskal-Wallis, $H=6.653$, $\mathrm{df}=2, \mathrm{p}<0.05$ ), GH (Kruskal-Wallis, $\mathrm{H}=6.709$, $\mathrm{df}=2$, $\mathrm{p}<0.05$ ), V (Kruskal-Wallis, $\mathrm{H}=16.774$, $\mathrm{df}=2, \mathrm{p}<$ 0.001), RE (Kruskal-Wallis, $\mathrm{H}=11.260, \mathrm{df}=2, \mathrm{p}<0.01$ ), and $\mathrm{MH}$ (Kruskal-Wallis, $\mathrm{H}=15.731, \mathrm{df}=2, \mathrm{p}<$ $0.001)$ between the three subgroups were found. No significant differences in BP (Kruskal-Wallis, $\mathrm{H}=4.060$, $\mathrm{df}=$ 2, $\mathrm{p}=0.131$ ) and $\mathrm{SF}$ (Kruskal-Wallis, $\mathrm{H}=3.397$, $\mathrm{df}=2$, $\mathrm{p}=0.183$ ) between the three subgroups were evident.

\section{Variables with a Possible Influence on the Risk of \\ PTSD}

Variables that may have contributed in some way to the development of posttraumatic stress symptoms in OLT recipients are depicted in tables 1 and 2. The diagnostic status of full or partial PTSD in our cohort of adult OLT recipients was not significantly related to any of the following variables: gender $\left(\chi^{2}=3.645, \mathrm{df}=2, \mathrm{p}=0.162\right)$, age (Kruskal-Wallis, $\mathrm{H}=3.244$, df $=2, \mathrm{p}=0.198$ ), employment status $\left(\chi^{2}=1.186, \mathrm{df}=2, \mathrm{p}=0.553\right)$, marital status $\left(\chi^{2}=7.295, \mathrm{df}=6, \mathrm{p}=0.294\right)$, number of months from OLT to psychiatric-psychometric assessment (Kruskal-Wallis, $\mathrm{H}=2.642, \mathrm{df}=2, \mathrm{p}=0.267$ ), primary liver disease $\left(\chi^{2}=9.531, \mathrm{df}=8, \mathrm{p}=0.300\right)$, type of liver failure $\left(\chi^{2}=2.610, \mathrm{df}=2, \mathrm{p}=0.271\right)$, history of retransplantation $\left(\chi^{2}=5.510, \mathrm{df}=2, \mathrm{p}=0.064\right)$, history of recurrence of HBV/HCV $\left(\chi^{2}=2.247, \mathrm{df}=2, \mathrm{p}=0.325\right)$, medical complications during ICU treatment following OLT in terms of gastrointestinal bleeding $\left(\chi^{2}=0.923, \mathrm{df}=2, \mathrm{p}=0.630\right)$, viral, mycotic or bacterial infections $\left(\chi^{2}=3.143, \mathrm{df}=2\right.$, $\mathrm{p}=0.208)$, acute cardiovascular disturbances $\left(\chi^{2}=1.884\right.$, $\mathrm{df}=2, \mathrm{p}=0.390)$, acute renal failure $\left(\chi^{2}=3.710, \mathrm{df}=2\right.$, $\mathrm{p}=0.156)$, delirium $\left(\chi^{2}=5.044, \mathrm{df}=2, \mathrm{p}=0.080\right)$, and acute respiratory stress syndrome $\left(\chi^{2}=2.391, \mathrm{df}=2, \mathrm{p}=\right.$ 0.303). The duration of ICU treatment following OLT (Kruskal-Wallis, $\mathrm{H}=8.951$, $\mathrm{df}=2, \mathrm{p}=0.011$ ), the total number of medical complications during ICU treatment (Kruskal-Wallis, $\mathrm{H}=6.491$, $\mathrm{df}=2, \mathrm{p}=0.039$ ), and the occurrence of acute rejection during ICU treatment subsequent to OLT $\left(\chi^{2}=6.858, \mathrm{df}=2, \mathrm{p}=0.032\right)$, however, were significantly positively correlated with the risk of 
Fig. 2. Comparison of the mean scores \pm standard errors of the SF-36 HRQOL questionnaire between the three subgroups of OLT recipients with no PTSD $(\mathrm{n}=58)$, partial PTSD $(n=13)$, and full PTSD $(n=4)$ at the time of psychiatric assessment. Normal score $=100$. Significant differences between groups were found on all domains but BP and SF.

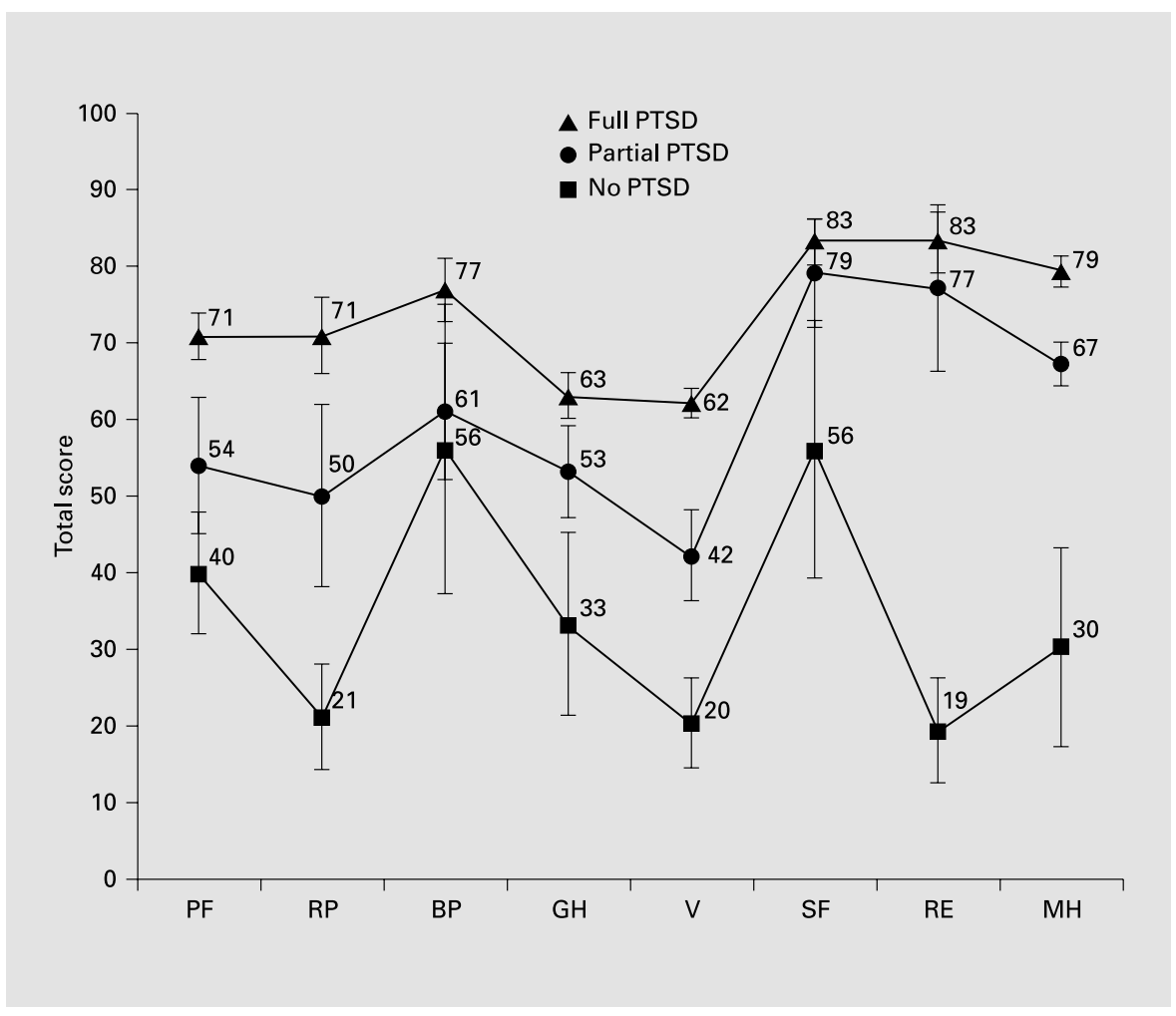

PTSD symptomatology following liver transplantation. The length of the waiting period for OLT was negatively correlated with the risk of partial and full PTSD (KruskalWallis, $\mathrm{H}=7.233$, $\mathrm{df}=2, \mathrm{p}=0.027$; patients with full PTSD: median $=8.5$ days; partial PTSD: median $=11$ days; no PTSD: median = 28 days); however, Bonferroni correction for pair-wise comparison showed no discrimination reaching statistical significance between the subgroups.

\section{Discussion}

Overall, the prevalence of psychiatric morbidity in this sample of adult liver transplant recipients identified by SCID according to DSM-III-R criteria was $22.7 \%$. This prevalence rate fell within the range for psychiatric morbidity in adult intermediate-term survivors of OLT reported in the two previous studies using Research Diagnostic Criteria (18.8\%) [20] or Clinical Interview Schedule $(26.7 \%)$ [21]. It was comparable with the prevalence rate of psychiatric morbidity in the general population, as found in a German epidemiological study [45]. In accordance with Commander et al. [20] and Collis et al. [21], we found that anxiety disorders and depression were the most frequent psychiatric diagnoses in OLT survivors.

$17.3 \%$ of the OLT recipients displayed mild signs of cognitive impairments at a median time of 3.8 years after liver transplantation; however, none of these patients fulfilled the criteria for any organic mental disorder according to DSM-III-R. This was a main finding in terms of the history of cognitive performance following OLT. As we know from studies targeting organic mental disorders in OLT candidates, the prevalence rate of delirium according to DSM-III ranged from 16.7 to $18.6 \%$ [46, 47]. Earlier reports of OLT recipients have even noted a $30-50 \%$ prevalence of delirium or encephalopathy [19, 48, 49]. Following OLT, Vieta et al. [18] reported a 13\% prevalence of delirium during the postoperative period until discharge, and at a median time of 39 weeks after OLT, Collis et al. [21] found a 3.3\% prevalence of organic mental disorder. OLT is obviously effective in reversing delirious states owing to hepatic encephalopathy, and it has been pointed out that improved neuropsychiatric function explained as much as $20 \%$ of improvement in quality of life in OLT recipients [50]. However, it has also been stated that cognitive functioning is restored to a large extent, but not completely, subsequent to OLT [51]. This 
observation concurs with our results. As we found a positive correlation between severity of PTSD symptoms and cognitive disturbances, it is conceivable that our observed cognitive impairments may be related to psychological distress in terms of PTSD symptoms. At least, Bremner's study [52] has demonstrated that PTSD may be associated with cognitive dysfunction.

The most interesting result of our study resides in the observation that a significant minority of the studied adult OLT survivors developed posttraumatic stress symptoms as a consequence of OLT. We found that 5.3\% of the patients met DSM-III-R criteria for a current diagnosis of full PTSD, and $17.3 \%$ of the patients for a partial PTSD at a median time of 3.8 years after OLT. Despite the increasing consideration of medically related posttraumatic stress symptoms in a large body of literature over the past 5 years, only three previous studies systematically addressed the issues of posttraumatic stress symptoms related to solid organ transplantation [24, 53, 54]. Walker et al. [24] interviewed 18 children aged between 7 and 16 years at a mean time of 16.94 months after liver transplantation by using the Child Posttraumatic Stress Reaction Index (CPTS-RI). The concordance between the CPTS-RI ratings and the DSM-III-R criteria for a diagnosis of PTSD has been found to be high [55]. The study demonstrated that $11 \%$ of the studied patients fell within the severe range of posttraumatic stress, $11 \%$ fell within the moderate range, and 56\% fell within the mild range. These results indicated that the acute life threat involved in the liver transplantation contributed to the development of posttraumatic stress. Using the PTSD module of the Composite International Diagnostic Interview (CIDI) [56] that yields a diagnosis of the disorder based on DSMIII-R criteria, Stukas et al. [53] found that $10.8 \%$ of the 158 studied heart transplant recipients met the full criteria for a diagnosis of PTSD, and an additional $5 \%$ of the patients were probable cases at 12 months after transplantation. Most recently, Grandi et al. [54] investigated 129 heart transplant recipients who had undergone transplantation 1 month previously. Using the Italian version of the SCID for the DSM-IV, they recorded a $26.3 \%$ figure of anxiety disorders in their sample. Full PTSD (7\%) and generalized anxiety disorder (7\%) constituted the most frequent diagnostic categories in their heart transplant recipients.

There are at least four possible explanations for the observed difference in full and partial PTSD prevalence rates across the studies. First, OLT recipients in the current study were interviewed at a median time of 46 months after OLT, whereas in the other studies, psychiat- ric assessments were conducted at $1,16.94$ or 12 months after solid organ transplantation. A recent epidemiological study has demonstrated that approximately $26 \%$ of PTSD cases remitted by 6 months, and $40 \%$ by 12 months, and even from that point on, remission continued, although it tapered off [57]. Reflecting this clinical course of PTSD, we could speculate that a portion of our studied patients suffering from a partial PTSD at the time the evaluation was conducted might have experienced a partial remission from a full PTSD over time. On the other hand, we have to state that our retrospective analysis of lifetime diagnoses by using SCID-I did not reveal a history of full PTSD in those patients meeting the criteria for a current partial PTSD. Second, we investigated adult OLT recipients with a mean age of 52.2 years, whereas Walker et al. [24] studied children with a mean age of 11.8 years. Published studies suggest that younger age represents an important risk factor for PTSD [58, 59]. Third, different types of physical traumata and medical illnesses may produce different rates of full PTSD and partial PTSD. For example, Kapfhammer et al. [60] found that $23.9 \%$ of the investigated 46 long-term survivors of the acute respiratory distress syndrome suffered from a full PTSD, and $17.8 \%$ from a partial PTSD, as detected by a full diagnostic assessment with the Structured Clinical Interview for DSM-IV, while Green et al. [61] described that only $2.5 \%$ of the studied 160 women with an early-stage breast cancer met stringent criteria for cancer-related PTSD according to DSM-III-R. Madianos et al. [62] examining 45 patients with burn injuries reported a $20 \%$ prevalence of PTSD according to DSM-III-R criteria. Fourth, our studied sample only included OLT recipients who had CsA or FK 506 concentrations in blood within therapeutic range. Hence, our participants represented a selected cohort of OLT recipients who were highly compliant with medications. One study has recently demonstrated that posttransplant medical compliance and mental health predicted physical morbidity and mortality $1-3$ years after heart transplantation, and that the risk of cardiac allograft disease was elevated by anxiety and depressive symptomatology [63]. Considering these results, one could speculate that those OLT recipients showing CsA or FK 506 blood levels not within the target range were noncompliant with immunosuppressive therapy owing to psychological factors such as depressive and anxiety disorders including PTSD. Mayou and Smith [64] emphasized that a partial or full syndrome of PTSD could be associated with avoidance of medical care and poor compliance with treatment. One study investigating the prevalence of noncompliance with immunosuppressive medication in 118 
OLT recipients documented a figure of $16 \%$ at a mean follow-up time of 53.7 months [65]. Given that OLT recipients with immunosuppressive concentrations in blood not within the target range were enrolled in our study, it is possible that the prevalence of full PTSD in OLT recipients may be similar to that observed in the study by Stukas et al. [53].

It is particularly noteworthy that $50 \%$ of our patients meeting DSM-III-R criteria for full PTSD were comorbid with major depression, while only $7.7 \%$ of those patients suffering from partial PTSD occurred with major depression. From a point of view of depression, it is worth considering that an additional $15.4 \%$ of the patients with partial PTSD scored 13 points or more on the HAMD 17 , indicating major depression. However, the $\mathrm{HAMD}_{17}$ scale was not designed to be used for diagnostic purposes and is only used for measuring the severity of symptoms once a diagnosis has been made. Therefore, our comorbidity data only partly concur with the observations made by Kessler et al. [66] in a recent epidemiologic survey. Considering the fact that $50 \%$ of our patients with full PTSD had lifetime histories of MDD, and only $23 \%$ of our patients with partial PTSD had lifetime histories of depressive disorders NOS, we could raise the hypothesis that patients with a personal psychiatric history of mood disorders might be more susceptible to the development of OLT-related PTSD than those without previous affective disorders. At least, our analysis of possible risk variables for PTSD symptomatology revealed that the length of ICU stay and number of complications during ICU did not significantly differ in our studied OLT recipients with full PTSD from those without PTSD, whereas patients with partial PTSD had been treated significantly longer in the ICU and had experienced significantly more complications during ICU than those without PTSD. We agree with Jacobsen et al. [67] that a longer treatment duration in the ICU is due to the increased incidence of medical complications that may be perceived as life-threatening associated with feelings of fear, helplessness or horror, and therefore may increase the potential for the development of PTSD symptomatology. Other variables that may contribute in some way to the development of PTSD symptoms such as gender, age, waiting period for OLT, primary liver disease, type of liver failure, history of retransplantation, and history of recurrence of $\mathrm{HBV} /$ $\mathrm{HCV}$ were not significantly different between the studied patients with full, partial, or no PTSD. Regarding the recurrence of $\mathrm{HBV} / \mathrm{HCV}$, it is worth discussing that this information is certainly associated with psychological distress for the patients as a rapid progression of the infec- tion cannot be ruled out; however, this stressor is a future-oriented one, since in most cases, prognosis is good and progression of liver disease is relatively slow. The nature of this stressor, therefore, may not fit the PTSD model well. Most interestingly, the occurrence of acute rejection during ICU treatment was a significant predictor of PTSD symptomatology. In fact, experiencing episodes of acute rejections played a major role for the OLT recipients' subjective perception of trauma. According to contemporary immunosuppressive strategies [68], patients with acute rejection were initially treated with pulse intravenous methylprednisolone, up to $1 \mathrm{~g}$ /day for 3 consecutive days. As we know from literature [69, 70], transient disruption of sleep, altered perception, and lability of mood often occurs among those receiving 'suprapharmacologic' doses of glucocorticoids as an antirejection therapy. Besides, from a psychobiological perspective, one could speculate that 'pulses' of glucocorticoids might have an influence on the development of PTSD symptomatology. Theoretically, glucocorticoid excess could have neurotoxic effects, particularly in the hippocampus, a primary neural glucocorticoid target site, and it has been hypothesized that hippocampal damage appears to be a correlate of PTSD itself, as decreased hippocampal functioning may cause behavioral disinhibition by promoting the definition of incoming stimuli in the direction of fight/ flight responses [71, 72]. However, the role of glucocorticoid pulse therapy in the development of PTSD seems to be very speculative because the role of glucocorticoids in PTSD is controversial, and, generally, the instances of glucocorticoid-induced hippocampal atrophy require prolonged or repeated bursts of glucocorticoid excess [73].

A major aim of the present study was to explore the relation between psychiatric morbidity in OLT recipients and HRQOL. HRQOL in the entire sample of our patients was characterized by statistically significant decrements in all eight domains of the SF-36 when compared with a German age and gender-matched healthy control group. This finding was only partly in accordance with the results reported by Bravata et al. [7] who quantitatively synthesized the complete published English-language literature on HRQOL after liver transplantation. They reported that the SF-36 scores from the studied 468 OLT recipients were not significantly different from those of the general US population, except in the pain domain. Besides, we found $64 \%$ employed at the time the evaluation was performed. This figure was quite similar to the average overall employment rates in other recent studies [74]. In accordance with the other two previous studies investigating the relation between psychiatric morbidity 
and HRQOL [20, 21], our study demonstrates that there was a significant association between psychiatric morbidity and impaired HRQOL. In detail, OLT recipients fulfilling DSM-III-R criteria for PTSD, either comorbid with MDD or not, manifested the most impaired mental and physical health status and perceived supportive relationships most unfavorably, followed by those with subthreshold expressions of PTSD, whereas OLT recipients without current or probable psychiatric disorders showed the most favorable health status. The finding regarding mental health subscales suggests that PTSD symptomatology subsequent to OLT is a clinically relevant phenomenon. So far as the physical health subscales are concerned, one could argue that either the presence of PTSD symptomatology had adverse health effects that made them less able to cope with activities in daily living, or that their physical health was worse and reminded them of traumatic aspects of their ICU treatment following OLT.

Finally, there are several limitations of this study to be respected. First, the varying time intervals between OLT and psychiatric evaluation. Second, the study was retrospective in design. A recall bias might have significantly lowered the report on any psychiatric disorder and traumatic experiences prior to and following OLT. Third, no pretransplant measures of psychiatric symptomatology and other psychosocial variables including SF-36 baseline data were available with which to compare our findings. Fourth, the sample was a selected cohort of OLT recipients. Although our decision to consider OLT recipients only eligible for enrollment if they had CsA or FK 506 concentrations in blood within therapeutic range certainly helped to avoid confounding present cognitive deficits, mood and anxiety phenomena with cyclosporine-associated or tacrolimus-associated organic mental disturbances; it is possible that the prevalence rate of PTSD symptomatology would have been higher if we had included patients who were not compliant with immunosuppressive medication. Fifth, the conduction of brain magnetic resonance imaging examining the hippocampus, psychophysiologic and endocrinological evaluations should be proposed in future studies in order to measure presumed neurobiological correlates of PTSD itself that could add objectivity to the assessment of PTSD. Sixth, the inclusion of appropriate control groups (e.g. heart transplant recipients) needs to be considered in forthcoming studies, and future research should also include longitudinal study designs. Seventh, the Diagnostic Criteria for Psychosomatic Research, as proposed by Fava et al. [75], should be used in future studies in order to improve the identification of psychological factors which could result in a worsening of HRQOL in OLT recipients [54, 76$78]$.

In conclusion, our study demonstrated that a subgroup of intermediate-term survivors of OLT exhibited PTSD symptomatology that was related to impaired HRQOL. This finding highlights the need to be aware of the possible presence of PTSD in OLT survivors who present to health-care providers with a variety of common psychiatric symptoms such as sleep difficulties and poor concentration. HRQOL may be improved in affected OLT recipients by attenuating posttraumatic stress symptoms. Definitive psychotherapeutical and pharmacotherapeutical treatment approaches for PTSD exist.

\section{Acknowledgments}

The authors wish to thank Prof. Dr. Monika Bullinger and Matthias Morfeld, MA, from the Institute of Medical Psychology, University Hospital Eppendorf, Hamburg, Germany, for providing control group data of the SF-36 health survey.

\section{References}

1 Wood RP, Ozaki CF, Katz SM, Monsour HP $\mathrm{Jr}$, Dyer CH, Johnston TD: Liver transplantation. The last ten years. Surg Clin of North Am 1994;74:1133-1154.

2 Seaberg EC, Belle SH, Beringer KC, Schivins JL, Detre KM: Long-term patient and retransplantation-free survival by selected recipient and donor characteristics: An update from the Pitt-UNOS liver transplant registry; in Cecka JM, Terasaki PI (eds): Clinical Transplants 1997. Los Angeles, UCLA Tissue Typing Laboratory, 1998, vol 13, pp 15-28.
3 Rust C, Rau H, Gerbes AL, Pape GR, Haller M, Kramling H, Schildberg FW, Paumgartner G, Beuers U: Liver transplantation in primary biliary cirrhosis: Risk assessment and 11-year follow-up. Digestion 2000;62:38-43.

4 Freeman AM 3rd, Westphal JR, Davis LL, Libb JW: The future of organ transplant psychiatry. Psychosomatics 1995;36:429-437.

5 Dew MA, Switzer GE, Goycoolea JM, Allen AS, DiMartini A, Kormos RL, Griffith BP: Does transplantation produce quality of life benefits? Transplantation 1997;64:12611273.
6 Tarter RE: Quality of life following liver transplantation. Hepatogastroenterology 1998;45: 1398-1403.

7 Bravata DM, Olkin I, Barnato AE, Keeffe EB, Owens DK: Health-related quality of life after liver transplantation: A meta-analysis. Liver Transpl Surg 1999;5:318-331.

8 Dickson RC, Wright RM, Bacchetta MD, Bodily SE, Caldwell SH, Driscoll CJ, Pruett TL, Ishitani MB: Quality of life of hepatitis B and $\mathrm{C}$ patients after liver transplantation. Clin Transplant 1997;11:282-285. 
9 Singh N, Gayowski T, Wagener MM, Marino IR: Quality of life, functional status, and depression in male liver transplant recipients with recurrent viral hepatitis $\mathrm{C}$. Transplantation 1999;67:69-72.

10 De Bona M, Ponton P, Ermani M, Iemmolo RM, Feltrin A, Boccagni P, Gerunda G, Naccarato $R$, Rupolo G, Burra P: The impact of liver disease and medical complications on quality of life and psychological distress before and after liver transplantation. J Hepatol 2000;33: 609-615.

11 Paterson DL, Gayowski T, Wannstedt CF, Wagener MM, Marino IR, Vargas H, Laskus T, Rakela J, Singh N: Quality of life in long-term survivors after liver transplantation: Impact of recurrent viral hepatitis $\mathrm{C}$ virus hepatitis. Clin Transplant 2000;14:48-54.

12 Craven JL: Cyclosporine-associated organic mental disorders in liver transplant recipients. Psychosomatics 1991;32:94-102.

13 DiMartini A, et al: Neuropsychiatric side effects of FK 506 vs. cyclosporin A. First-week postoperative findings. Psychosomatics 1997; 38:565-569

14 Gijtenbeek JMM, van den Bent MJ, Vecht CJ Cyclosporine neurotoxicity: A review. J Neurol 1999;246:339-346.

15 Brown ES, Suppers T: Mood symptoms during corticosteroid therapy: A review. Harv Rev Psychiatry 1998;5:239-246.

16 Greiner CB, Roccaforte W: Psychiatric issues in liver transplantation. Semin Liver Dis 1989 ; 9:184-188.

17 Surman OS: Psychiatric aspects of liver transplantation. Psychosomatics 1994;35:297-307.

18 Vieta E, de Pablo J, Cirera E, Pujol A, Grande L, Rimola A, Visa J: Postoperative psychiatric complications following liver transplantation. Med Clin (Barc) 1993;100:210-213.

19 Surman OS, Dienstag JL, Cosimi AB, Chauncey S, Russell PS: Psychosomatic aspects of liver transplantation. Psychother Psychosom 1987;48:26-31.

20 Commander M, Neuberger J, Dean C: Psychiatric and social consequences of liver transplantation. Transplantation 1992;53:10381040.

21 Collis I, Burroughs A, Rolles K, Lloyd G: Psychiatric and social outcome of liver transplantation. Br J Psychiatry 1995; 166:521-524.

22 Spitzer RL, Endicott J, Robins E: Research diagnostic criteria: Rationale and reliability. Arch Gen Psychiatry 1978;35:773-782.

23 Goldberg D, Cooper B, Eastwood MR, Kedward HB, Shepherd M: A standardized psychiatric interview for use in community surveys. Br J Prev Soc Med 1970;24:18-23.

24 Walker AM, Harris G, Baker A, Kelly D, Houghton J: Post-traumatic stress responses following liver transplantation in older children. J Child Psychol Psychiatry 1999;40:363374.

25 World Health Organization: International Classification of Impairments, Disabilities, and Handicaps. A Manual of Classification Relating to the Consequences of Disease. Geneva, World Health Organization, 1982.
26 Spitzer RL, Williams JBW, Gibbon M, First MB: Structured Clinical Interview for DSMIII-R, Patient Edition (SCID-P, Version 1.0). Washington, American Psychiatric Press, 1990.

27 Wittchen HU, Zaudig M, Schramm E, Spengler P, Mombour W, Klug J, Horn R: Strukturiertes klinisches Interview für DSM-III-R (SKID). Weinheim, Beltz Test Gesellschaft, 1991.

28 American Psychiatric Association: Diagnostic and Statistical Manual of Mental Disorders, ed 3, revised. Washington, American Psychiatric Press, 1987.

29 American Psychiatric Association: Diagnostic and Statistical Manual of Mental Disorders, ed 4. Washington, American Psychiatric Press, 1994.

30 Erzigkeit H: SKT - Ein Kurztest zur Erfassung von Gedächtnis- und Aufmerksamkeitsstörungen. Weinheim, Beltz, 1989.

31 Overall JE, Schaltenbrand R: The SKT neuropsychological test battery. J Geriatr Psychiatry Neurol 1992;5:220-227.

32 Lehfeld H, Erzigkeit H: The SKT: A short cognitive performance test for assessing deficits of memory and attention. Int Psychogeriatr 1997; 9(suppl 1):115-121.

33 Hamilton M: Development of a rating scale for primary depressive illness. Br J Soc Clin Psychol 1967;6:278-296.

34 Möller HJ: Methodological aspects in the assessment of severity of depression by the Hamilton Depression Scale. Eur Arch Psychiatry Clin Neurosci 2001;251(suppl 2):13-20.

35 Paykel ES: Use of the Hamilton Depression Scale in general practice. Psychopharmacol Ser 1990;9:40-47.

36 American Psychiatric Association: Diagnostic and Statistical Manual of Mental Disorders, ed 3. Washington, American Psychiatric Press, 1980 .

37 Weisaeth L: Torture of a Norwegian ship's crew. The torture, stress reactions and psychiatric after-effects. Acta Psychiatr Scand Suppl 1989;355:63-72.

38 Stoll C, Kapfhammer HP, Rothenhäusler HB, Haller M, Briegel J, Schmidt M, Krauseneck T, Durst K, Schelling G: Sensitivity and specificity of a screening test to document traumatic experiences and to diagnose post-traumatic stress disorder in patients after intensive care treatment. Intensive Care Med 1999;25:697704.

39 Donald CA, Ware JE: The measurement of social support. Res Commun Ment Health 1984;4:325-370.

40 Kirchberger J, Bullinger M: Der Social Support Fragebogen. Göttingen, Hogrefe, 2001.

41 Stewart A, Hays R, Ware JE Jr: The MOS short-form general health survey. Reliability and validity in a patient population. Med Care 1988;26:724-732.

42 Bullinger M, Kirchberger I: Der SF-36 Fragebogen zum Gesundheitszustand. Göttingen, Hogreve, 1998.
43 Ware JE Jr, Sherbourne C: The MOS 36-item short-form healthy survey. 1. Conceptual framework and item selection. Med Care 1992; 30:473-483.

44 Schelling G, Stoll C, Haller M, Briegel J, Manert W, Hummel T, Lenhart A, Heyduck M, Polasek J, Meier M, Preuss U, Bullinger M, Schüffel W, Peter K: Health-related quality of life and post-traumatic stress disorder in survivors of the acute respiratory distress syndrome. Crit Care Med 1998;26:651-659.

45 Fichter MM, Narrow WE, Roper MT, Rehm J, Elton M, Rae DS, Locke BZ, Regier DA: Prevalence of mental illness in Germany and the United States. Comparison of the Upper Bavarian Study and the Epidemiologic Catchment Area Program. J Nerv Ment Dis 1996; 184:598-606

46 Trzepacz PT, Brenner RP, Coffman G, Van Thiel DH: Delirium in liver transplantation candidates: Discrimination analysis of multiple test variables. Biol Psychiatry 1988;24:314

47 Trzepacz PT, Brenner RP, Van Thiel DH: A psychiatric study of 247 liver transplantation candidates. Psychosomatics 1989;30:147-153.

48 House R, Dubovsky SL, Penn I: Psychiatric aspects of hepatic transplantation. Transplantation 1983;36:146-150.

49 Trzepacz PT, Maue FR, Coffman G, Van Thiel DH: Neuropsychiatric assessment of liver transplantation candidates: Delirium and other psychiatric disorders. Int $\mathrm{J}$ Psychiatry Med 1986;16:101-111.

50 Tarter RE, Switala J, Plail J, Havrilla J, Van Thiel DH: Severity of hepatic encephalopathy before liver transplantation is associated with quality of life after transplantation. Arch Intern Med 1992;152:2097-2101.

51 Tarter RE, Switala JA, Arria A, Plail J, Van Thiel DH: Subclinical hepatic encephalopathy. Comparison before and after orthotopic liver transplantation. Transplantation 1990;50: 632-637.

52 Bremner JD: Alterations in brain structure and function associated with post-traumatic stress disorder. Semin Clin Neuropsychiatry 1999;4: 249-255.

53 Stukas AA, Dew MA, Switzer GE, DiMartini A, Kormos RL, Griffith BP: PTSD in heart transplant recipients and their primary family caregivers. Psychosomatics 1999;40:212-221.

54 Grandi S, Fabbri S, Tossani E, Mangelli L, Branzi A, Magelli C: Psychological evaluation after cardiac transplantation: The integration of different criteria. Psychother Psychosom 2001;70:176-183.

55 Pynoos RS, Goenjian A, Tashjian M, Karakashian M, Manjikian R, Manoukian G, Steinberg AM, Fairbanks LA: Post-traumatic stress reactions in children after the 1988 Armenian earthquake. Br J Psychiatry 1993;163:239_ 247.

56 World Health Organization: Composite International Diagnostic Interview (CIDI), Version 1.0. Geneva, World Health Organization, 1990 
57 Breslau N, Kessler RC, Chilcoat HD, Schultz LR, Davis GC, Andreski P: Trauma and posttraumatic stress disorder in the community: The 1996 Detroit Area Survey of Trauma. Arch Gen Psychiatry 1998;55:626-632.

58 Green BL, Grace MC, Lindy JD, Gleser GC, Leonhard A: Risk factors for PTSD and other diagnoses in a general sample of Vietnam veterans. Am J Psychiatry 1990;147:729-733.

59 Norris FH: Epidemiology of trauma: Frequency and impact of different potentially traumatic events on different demographic groups. J Consult Clin Psychol 1992;60:409-418.

60 Kapfhammer HP, Rothenhäusler HB, Krauseneck T, Stoll C, Schelling G: Posttraumatic stress disorder and health-related quality of life in long-term survivors of acute respiratory distress syndrome. Am J Psychiatry 2002; in press.

61 Green BL, Rowland JH, Krupnick JL, Epstein SA, Stockton P, Stern NM, Spertus IL, Steakley C: Prevalence of posttraumatic stress disorder in women with breast cancer. Psychosomatics 1998;39:102-111.

62 Madianos MG, Papaghelis M, Ionnovich J, Dafni R: Psychiatric disorders in burn patients: A follow-up study. Psychother Psychosom 2001;70:30-37.

63 Dew MA, Kormos RL, Roth LH, Murali S, DiMartini A, Griffith BP: Early post-transplant medical compliance and mental health predict physical morbidity and mortality one to three years after heart transplantation. $\mathrm{J}$ Heart Lung Transplant 1999;18:549-562.
64 Mayou R, Smith KA: Post-traumatic symptoms following medical illness and treatment. J Psychosom Res 1997;43:121-123.

65 Berlakovich GA, Langer F, Freundorfer E, Windhager T, Rockenschaub S, Sporn E, Soliman T, Pokorny H, Steininger R, Mühlbacher F: General compliance after liver transplantation for alcoholic cirrhosis. Transpl Int 2000; 13:129-135.

66 Kessler R, Sonnega A, Bromet E, Highes M, Nelson CB: Posttraumatic stress disorder in the National Comorbidity Survey. Arch Gen Psychiatry 1995;52:1048-1060.

67 Jacobsen PB, Widows MR, Hann DM, Andrykowski MA, Kronish LE, Fields KK: Posttraumatic stress disorder symptoms after bone marrow transplantation for breast cancer. Psychosom Med 1998;60:366-371.

68 Elias E: Liver transplantation. J R Coll of Physicians Lond 1993;27:224-232.

69 Surman OS: Psychiatric aspects of organ transplantation. Am J Psychiatry 1989;146:972982.

70 Kershner P, Wang-Cheng R: Psychiatric side effects of steroid therapy. Psychosomatics 1989;30:135-139.

71 Squire LR, Zola-Morgan S: The medial temporal lobe memory system. Science 1991;253: 2380-2386.
72 Van der Kolk BA: The psychobiology of posttraumatic stress disorder. J Clin Psychiatry 1997;58(suppl 9):16-24.

73 Sapolsky RM: Glucocorticoids and hippocampal atrophy in neuropsychiatric disorders. Arch Gen Psychiatry 2000;57:925-935.

74 Bravata DM, Olkin I, Barnato AE, Keeffe EB, Owens DK: Employment and alcohol use after liver transplantation for alcoholic and nonalcoholic liver disease: A systematic review. Liver Transpl 2001;7:191-203.

75 Fava GA, Freyberger H, Bech P, Christodoulou G, Sensky T, Theorell T, Wise TN: Diagnostic criteria for use in psychosomatic research. Psychother Psychosom 1995;63:1-8.

76 Fava GA, Mangelli L, Ruini C: Assessment of psychological distress in the setting of medical disease. Psychother Psychosom 2001;70:171175.

77 Porcelli P, De Carne M, Fava GA: Assessing somatization in functional gastrointestinal disorders. Psychother Psychosom 2000;69:198204.

78 Porcelli P, De Carne M: Criterion-related validity of the diagnostic criteria for psychosomatic research for alexithymia in patients with functional gastrointestinal disorders. Psychother Psychosom 2001;70:184-188. 